\title{
Susan E. Jackson, Deniz S. Ones and Stephan Dilchert (Eds.): Managing Human Resources for Environment Sustainability
}

\author{
Ken Jones
}

Published online: 6 March 2013

(c) Springer-Verlag Berlin Heidelberg 2013

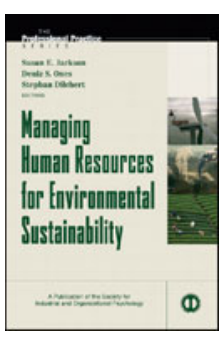

Bibliography

Managing Human Resources for

Environment Sustainability

Susan E. Jackson, Deniz S.

Ones and Stephan Dilchert (Eds.)

Jossey-Bass, A Wiley Imprint,

San Francisco, CA, USA, 2012, pp xxxxix +456

ISBN 978-0-470-88720-2

USD 90.00, EUR 72.00

Industrial and Organisational (I-O) psychology and human resource management (HR) is a 'left-of-field' region to most conventional scientists; but does it have relevance? Three editors have collated and reviewed forty-three highly qualified authors, with a foreword that states "there are very few 'game changers' in the fields of I-O psychology and HR management-and this subject is such a change". They claim it is a new way of thinking, with ideas that are fresh and revolutionary, whilst providing a description of the major changes currently taking place in how we deal with the many environmental issues that indirectly affect our lives. Presentation is compiled into four sections: The Imperative for Environmental Sustainability, Theoretical and Empirical Foundation to Guide Environmental Initiatives, Case Studies Illustrating the Implementation of Environmental Initiatives and Future Directions.

The awakening of the general public towards environmental issues, constantly fed by the propaganda from pressure groups and government sources often featuring doomsday scenarios ('optimism does not produce a headline'), has at least led to a huge effort in recycling the waste that previously was buried in landfill. In many circles, the

K. Jones $(\bowtie)$

Knutsford, Cheshire, UK

e-mail: Chromatographia@springer.com propaganda element has worn somewhat thin, but the message here is to switch to a less hysterical, more practical, measured response.

Scientists have dealt with environmental issues long before they entered the public consciousness. Accurate tailpipe monitoring only became possible with the advent of $\mathrm{GC}$, which led to the first legislation enacted in California more than 50 years ago. As legislation tightened, chemical plants and refineries became targets, so scientists had to rapidly become "green". However, their role was an enjoyable challenge; the creation and development of ever more sensitive, reliable, quantifiable, instruments and techniques-so, what HR managers think today as revolutionary is evolutionary to scientists.

This is not to decry the thrust of these authors. Public awareness has been enormously increased, and driving this through company management to the highest level is revolutionary. By dividing the issues into categories of air, water, nuclear, and climate, a series of certifications for environmental management has emerged: ISO 14001. However, the EU has also developed its own certification processes: EMA's, GRI Index, and the SAM Index. Only time will tell whether all the latter are simply more European red tape, or a constructive approach to resolving public concerns.

The case studies are very illuminating. Most of the giant companies involved (3 M, Daimler, McDonalds UK, P\&G, Sherwin Williams, Ugandan Light Industry), describe massive savings by recycling and energy conservation often exceeding $50 \%$. However, there again, have we not all observed profligate waste in real life, but been unable to persuade management to take the necessary action? If you share this view then the book succeeds. Its objective is to place the environment at the centre of company policy, and implementing action whilst saving expenditure-a very worthy target. 